\title{
Epidemiological Features and Clinical Repercussions of Supernumerary Teeth in a Multicenter Study: A Review of 518 Patients with Hyperdontia in Spanish Population
}

Jorge Cortés-Bretón Brinkmann ～Natalia Martínez-Rodríguez¹ María Martín-Ares ${ }^{1} \quad$ Javier Sanz-Alonso Juan Santos Marino² Maria Jesús Suárez García $\quad$ Cristina Barona Dorado $\quad$ Jose María Martínez-González ${ }^{1}$

\footnotetext{
${ }^{1}$ Department of Dental Clinical Specialties, Faculty of Dentistry, Complutense University of Madrid, Madrid, Spain

${ }^{2}$ Division of Oral Surgery, Department of Surgery, University of Salamanca, Salamanca, Spain

${ }^{3}$ Department of Conservative Dentistry and Orofacial

Prosthodontics, Faculty of Dentistry, Complutense University of

Madrid, Madrid, Spain
}

Eur J Dent:2020;14:415-422

\begin{abstract}
Address for correspondence Jorge Cortés-Bretón Brinkmann, DDS, PhD, Department of Dental Clinical Specialties, Faculty of Dentistry, Complutense University of Madrid, Pza Ramon y Cajal s/n, 28040 Madrid, Spain (e-mail: brinkmann55@hotmail.com).
\end{abstract}

\section{Abstract}

Keywords

- clinical repercussions

- epidemiological features

- multicenter study

- Spanish population

- pathology

- supernumerary teeth
Objectives The aim of this study was to establish the prevalence of supernumerary teeth (ST) in a sector of the population of Madrid, as well as possible complications associated with the presence of these teeth.

Materials and Methods The study investigated patients $(n=28,114)$ who sought dental care at the Oral Surgery Service of three different centers between May 2005 and April 2018. Cases that did not present this numeric dental developmental variation were discarded, registering only those presenting ST.

Statistical Analysis Statistical analysis consisted of univariate analysis (mean, standard deviation, median, etc.), bivariate analysis applying the chi-squared test, whereby statistical significance was established with a confidence interval $(\mathrm{Cl})$ of $95 \%(p<0.05)$, and multivariate analysis by means of classification and decision trees.

Results The study found ST in 518 patients, representing a prevalence of $1.84 \%$. The 518 patients presented a total of 726 ST. Distomolars were the most common, representing $37.7 \%$ of the sample, followed by premolars $(20.1 \%)$. About $70.5 \%$ of the sample were located in the maxilla and $78 \%$ of ST were impacted. Radiographs revealed that $39.7 \%$ of STs were associated with disorders. Supplementary morphology appeared in $52.1 \%$ of the sample.

Conclusions Although mesiodens is considered the most common ST, the present study found distomolars and supernumerary premolars to be the most frequently occurring. Pathology was associated with $39.7 \%$ of the ST sample. Early diagnosis allows optimal patient management and treatment planning, with intervention at an appropriate time to prevent complications in development and so reduce later treatment need.
DOI https://doi.org/ $10.1055 / \mathrm{s}-0040-1712860$ ISSN $1305-7456$.
(C)2020 Dental Investigation Society
License terms

(1) (1) $\ominus \circledast$ 


\section{Introduction}

Hyperdontia, hypergenesis, or the presence of supernumerary teeth (ST) is defined as the existence of a number of teeth exceeding the normal dental formula. ${ }^{1-3}$ Orhan et $\mathrm{al}^{4}$ consider that ST are present when they exceed 20 in temporary dentition and 32 in permanent dentition. However, it is important to specify any increase in a particular dental group as ST may coexist with dental agenesis, although this is an extremely rare developmental disorder, named by Camilleri ${ }^{5}$ as concomitant hypo-hyperdontia.

ST are a relatively common developmental variation ${ }^{6-9}$ with a prevalence between $0.15 \%$ and $3.9 \%$ in permanent dentition, which appears to have increased in recent years. ${ }^{10-12}$ In addition to racial variations, age differences among patients, varying study protocols, and diagnostic methods may explain the wide range of prevalence cited in the literature. Different authors mention a higher frequency of ST in East Asian racial groups ${ }^{13,14}$ or racial groups of African origin ${ }^{15,16}$ in comparison with whites.

The etiology of ST within the population is multifactorial with evidence of chromosomal, polygenic, single gene, and major environmental influences in this complex etiology; different factors may exert a major influence on different individuals. ${ }^{17}$ Variation in outcome in a developmental process, such as the formation of the dentition, enables adaptation to different environments. Tooth number, size, and shape are determined during the initiation and morphogenetic stages of dental development. The molecular evidence of repetitive signaling throughout initiation and morphogenesis is reflected clinically in the association of anomalies of number, size, and shape.

This study set out to determine the prevalence of ST in a sector of the population of Madrid, as well as possible complications associated with the presence of these hypergenetic teeth. In addition, the results were compared statistically with the data obtained in similar studies conducted around the world.

\section{Materials and Methods}

This descriptive, retrospective-casuistic, multicenter study investigated a patient population in Madrid (Spain), all seeking dental care at the Oral Surgery Service of the Faculty of Dentistry at the Complutense University of Madrid (Spain), and at the oral surgery and implantology services of two hospitals: Virgen de La Paloma Hospital and Madrid Hospital.

The Complutense University of Madrid Ethics Committee approved the study protocol (Ref. 17/050E).

The study included all patients (a total of 28,114 individuals) who sought dental care at the oral surgery services of one of these three centers between May 2005 and December 2017 and whose medical notes included a panoramic radiograph, as well as a periapical or occlusal radiograph taken by the radiodiagnostic services of the same center. In those cases where the information was not accurate, additional information was requested in the form of a cone beam computed tomography scan; these findings were verified after surgical extraction of the ST.
Cases that did not present ST were discarded; the study sample was made up of patients who did present this developmental anomaly.

As exclusion criteria, patients presenting any genetic syndrome or congenital craniofacial anomaly generally associated with hyperdontia were excluded.

A clinical protocol was created for each patient registering the following data: medical record number, age, and sex; type of each ST: mesiodens, premolar, distomolar, or paramolar; location of ST: maxilla or mandible; eruption state: impacted or erupted; associated clinical or radiographic complications: mechanical obstructive pathology (MOP) or follicular sac enlargement (FSE) >3 mm; ST morphology: supplementary (when the ST adopt the same shape and size as the other teeth of the group it belongs to) or heteromorphic.

The radiographic tests were analyzed by the same researcher. Doubts arising were resolved by discussion and consensus among the team members of the research project.

All data were entered on a spreadsheet (Ms-Excel) and subsequently imported into the SPSS version 25.0 for Windows statistical software package.

Statistical analysis consisted of univariate analysis (mean, standard deviation, median, etc.), bivariate analysis applying the chi-squared test, whereby statistical significance was established with a confidence interval of $95 \%(p<0.05)$, and multivariate analysis by means of classification and decision trees.

\section{Results}

\section{Univariate Analysis}

The study's results showed the existence of ST in 518 patients, representing a prevalence of $1.84 \%$ of the total study population.

As for distribution by patient sex, 314 cases were male (60.62\%) and 204 were females (39.38\%), with a proportion $\mathrm{M} / \mathrm{F}$ of $1.54 / 1$. Patients' ages ranged from 5 to 75 years, with a mean age of 24.28 years.

Of these 518 patients, a total of 726 ST were found with the following distribution: $71.8 \%$ of patients presented a single ST, $23.2 \%$ presented two STs, and $5 \%$ of patients presented multiple hyperdontia with three or more STs, without any association with some complex syndrome (any such patients having been discarded as a result of the application of exclusion criteria).

Distomolars (37.7\%) were the most frequent ST, followed by premolars $(20.1 \%)$, mesiodens $(19.8 \%)$, and paramolars (9.9\%).

As for the distribution of ST (maxilla or mandible), maxillary distomolars were the most common (30.3\%), followed by mesiodens (19.8\%), and mandibular premolars (17.9\%). Out of the whole sample, 512 STs were located in the maxilla (70,5\%) and only 214 in the mandible (29.5\%).

Seventy-eight percent of STs were impacted and 22\% erupted.

Radiographic observation identified associated pathology in 288 STs, representing $39.7 \%$ of all the STs included in the study. FSE $>3 \mathrm{~mm}$ was found in $13.5 \%$ of the sample and MOP 
in $25.1 \%$. A small number (1.1\%) were associated with both ESF $>3 \mathrm{~mm}$ and MOP.

In analysis of ST morphology, 378 STs (52.1\%) presented supplementary morphology and 348 STs (47.9\%) heteromorphic morphology.

\section{Bivariate Analysis}

Bivariate analysis indicated a $95 \%$ statistically significant relationship ( $p=0.000$ ) between the type of ST and maxillary or mandibular location. Most distomolars (80.3\%; 220 out of 274 ) were found in the maxilla, while $89 \%$ of supernumerary premolars were located in the mandible.

A 95\% statistically significant relation $(p=0.000)$ was also observed between the type of ST and associated pathology (-Table 1). In this way, $26 \%$ of supernumerary premolars were associated with FSE $\geq 3 \mathrm{~mm}$, premolars being the ST with the greatest capacity to provoke follicular degeneration, followed by distomolars (19\%) and canines (15.4\%). Meanwhile, the paramolar showed the greatest association (58.3\%) with MOP, followed by lateral incisors (42.9\%), canines (38.5\%), and mesiodens (36.1\%).

A statistically significant relationship was observed $(95 \% ; p=0.000)$ between the location of STs (maxillary or mandibular) and associated pathology (-Table 2). More FSE $\geq 3 \mathrm{~mm}$ were located in the mandible (23.4\%), while maxillary STs were more often associated with MOP (30.5\%). At the same manner, a statistically significant relation was observed (95\%; $p=0.000$ ) between ST type and morphology. A $91.7 \%$ of paramolars and $86.1 \%$ of mesiodens presented heteromorphic morphology. Meanwhile, a $100 \%$ of upper lateral incisors and $90.4 \%$ of supernumerary premolars had identical shapes to their homologous teeth

\section{Discussion}

The presence of ST is usually discovered casually in the course of routine radiographic observation. Clinically, STs may manifest in the form of eruptive disorders of the adjacent teeth, in which case radiological examination will be conducted, leading to their discovery.

Although their prevalence is low $-1.84 \%$ according to the present results conducted among a Caucasian (Spanish) population-prevalence may reach $2.2 \%$ or even $3.5 \%$, as affirmed by Peltola, ${ }^{18}$ studying a Finnish population, and Ezoddini et $\mathrm{al}^{10}$ studying a Middle Eastern population, respectively.

Differences in prevalence in relation to sex are not in question, as most authors have found a clear male predominance. In the present study, the ratio of male to female was 1.54/1, which concurs with results obtained by Salcido-García et al ${ }^{9}$ and Rajab and Hamdan, ${ }^{19}$ among others.

The present study differed from other similar studies in the predominance of ST type. In most similar works, mesiodens occupies first place as the most frequently occurring ST type, usually followed by distomolars or premolars. According to Danalli et al, ${ }^{20}$ mesiodens represents $80 \%$ of all ST. Other authors such as Anthonappa et al, ${ }^{21}$ Liu et $a l,{ }^{22}$ and De Oliveira Gomes et $\mathrm{al}^{23}$ affirm that around 95\% of ST are situated in the premaxilla.

Table 1 Contingency table. Type of supernumerary teeth versus associated pathology

\begin{tabular}{|c|c|c|c|c|c|c|c|}
\hline & & & & Associat & pathology & & Total \\
\hline & & & $\begin{array}{l}\text { No of } \\
\text { pathology }\end{array}$ & $\begin{array}{l}\text { Mechanical } \\
\text { pathology }\end{array}$ & $\mathrm{FSE} \geq 3 \mathrm{~mm}$ & $\begin{array}{l}\text { FSE } \\
\geq 3 \mathrm{~mm}+ \\
\text { mechanical } \\
\text { pathology }\end{array}$ & number \\
\hline Type & Canines & Recount & 10 & 10 & 4 & 2 & 26 \\
\hline & & $\%$ within the type & 38.5 & 38.5 & 15.4 & 7.7 & 100.0 \\
\hline & Primary & Recount & 16 & 0 & 0 & 0 & 16 \\
\hline & & $\%$ within the type & 100.0 & 0.0 & 0.0 & 0.0 & 100.0 \\
\hline & Distomolars & Recount & 158 & 58 & 52 & 6 & 274 \\
\hline & & $\%$ within the type & 57.7 & 21.2 & 19.0 & 2.2 & 100.0 \\
\hline & Lower & Recount & 16 & 4 & 0 & 0 & 20 \\
\hline & incisives & $\%$ within the type & 80.0 & 20.0 & 0.0 & 0.0 & 100.0 \\
\hline & Lateral & Recount & 16 & 12 & 0 & 0 & 28 \\
\hline & incisores & $\%$ within the type & 57.1 & 42.9 & 0.0 & 0.0 & 100.0 \\
\hline & Mesiodens & Recount & 92 & 52 & 0 & 0 & 144 \\
\hline & & $\%$ within the type & 63.9 & 36.1 & 0.0 & 0.0 & 100.0 \\
\hline & Paramolars & Recount & 27 & 42 & 4 & 0 & 73 \\
\hline & & $\%$ within the type & 36.1 & 58.3 & 5.6 & 0.0 & 100.0 \\
\hline & Premolars & Recount & 103 & 4 & 38 & 0 & 145 \\
\hline & & $\%$ within the type & 71.2 & 2.7 & 26. & 0.0 & 100.0 \\
\hline & Total & Recount & 438 & 182 & 98 & 8 & 726 \\
\hline & & $\%$ within the type & 60.3 & 25.1 & 13.5 & 1.1 & 100.0 \\
\hline
\end{tabular}


Table 2 Contingency table. Location of supernumerary teeth versus associated pathology

\begin{tabular}{|c|c|c|c|c|c|c|c|}
\hline & & & \multicolumn{4}{|c|}{ Associated pathology } & \multirow[t]{2}{*}{ Total number } \\
\hline & & & $\begin{array}{l}\text { No of } \\
\text { pathology }\end{array}$ & $\begin{array}{l}\text { Mechanical/ } \\
\text { obstructive } \\
\text { pathology }\end{array}$ & $\mathrm{FSE} \geq 3 \mathrm{~mm}$ & $\begin{array}{l}\text { FSE } \geq 3 \mathrm{~mm}+ \\
\text { mechanical/ } \\
\text { obstructive } \\
\text { pathology }\end{array}$ & \\
\hline \multirow[t]{4}{*}{ MAXMAND } & \multirow[t]{2}{*}{ MAND } & Recount & 130 & 26 & 50 & 8 & 214 \\
\hline & & $\begin{array}{l}\% \text { within } \\
\text { MAXMAND }\end{array}$ & 60.7 & 12.1 & 23.4 & 3.7 & 100.0 \\
\hline & \multirow[t]{2}{*}{ MAX } & Recount & 308 & 156 & 48 & 0 & 512 \\
\hline & & $\begin{array}{l}\% \text { within } \\
\text { MAXMAND }\end{array}$ & 60.2 & 30.5 & 9.4 & 0.0 & 100.0 \\
\hline \multirow{2}{*}{\multicolumn{2}{|c|}{ Total }} & Recount & 438 & 182 & 98 & 8 & 726 \\
\hline & & $\begin{array}{l}\% \text { within } \\
\text { MAXMAND }\end{array}$ & 60.3 & 25.1 & 13.5 & 1.1 & 100.0 \\
\hline
\end{tabular}

Abbreviations: FSE, follicular sac enlargement; Mand, mandibular; Max, maxillary.

In the present study, the most frequent STs were distomolars (representing $37.7 \%)$, followed by premolars $(20,1 \%)$, mesiodens (19.8\%), paramolars (9.9\%), lateral incisors $(3.9 \%)$, canines $(3.6 \%)$, lower incisors $(2.8 \%)$, and temporary teeth (2.2\%). The low percentage of mesiodens registered in the present study is remarkable (only $19.8 \%$ ).

If the STs appearing in molar regions are counted, regardless of they are disto/paramolars, the percentage increases to $47.6 \%$ of the sample. It should be taken into account that the present study was conducted among patients attending three oral surgery/implantology services where third molar extraction is the treatment in most demand. Given that the mean age of the 28,114 patients included in the study was 34.65 years, a higher prevalence of late-developing ST such as distomolars or premolars could be expected. At the same time, it could be that the percentage of mesiodens was lower $(19.8 \%)$ than in other studies conducted among children, as it is possible (together with other factors) that these teeth had already been extracted.

This might also have a bearing on the fact that there was a statistically significant relationship between patient age and ST type. Mesiodens were the most frequently occurring STs among patients aged under 20 years (42.1\%), while distomolars were the most frequently found in older age ranges. In the 20 to 30 years range distomolars represented $52.3 \%$ of all ST; in patients aged over 30 years, distomolars made up $35.7 \%$ of the sample, while premolars increased to $29.8 \%$ of the sample in this age range.

This agrees with Leco Berrocal et $\mathrm{a}^{24}$ who also considered that upper distomolars were the most frequently occurring ST (38\%), followed by mesiodens (28.6\%) and lower premolars (14.2\%). Burgess ${ }^{25}$ found that $37.5 \%$ of STs were distomolars, Bereket et al $^{26} 22.36 \%$, while Fernández Montenegro et $\mathrm{al}^{27}$ and Dauder et $\mathrm{al}^{28}$ obtained approximately $18 \%$, and Tochihara ${ }^{29} 15.6 \%$.

The maxillary presents a higher frequency of ST than the mandible in a proportion that varies between 5 to 1 and 10 to 1 depending on the results obtained by different researchers.
Liu et $\mathrm{a}^{22}$ obtained a very high incidence of STs in the maxillary, in detail $97.12 \%$. De Oliveira Gomes et al $^{23}$ found $91.3 \%$ of STs in the maxilla. In the present study, $70.5 \%$ of STs were located in the maxilla and $29.5 \%$ in the mandible, results that concur with Celikoglu et al, ${ }^{30}$ who found $68.8 \%$ of STs in the maxilla.

We also identified a statistically significant relationship ( $p=0.000$ ) between ST type and maxillary or mandibular location. It was found that $80.3 \%$ of distomolars included in the study (220 out of 274) were located in the maxilla (-Fig. 1), while $89 \%$ of supernumerary premolars were located in the mandible (-Fig. 2 ). If paramolars are added to this analysis ( $n=72$ ), the percentage of supernumerary molars in the maxilla rises to $84 \%$. Grimanis et al $^{31}$ found that $79.7 \%$ of supernumerary molars were located in the maxilla. Tochihara ${ }^{29}$ observed an even higher percentage of maxillary location: $93.82 \%$.

Supernumerary premolars, unlike other types of ST, are more frequent in the mandible than the maxilla making them the most prevalent mandibular ST. ${ }^{32-34}$ In the present study, $89 \%$ of supernumerary premolars were located in the mandible; these mandibular premolars $(n=130)$ represented $60.5 \%$ of all mandibular STs $(n=214)$.

According to the literature, almost one-third of patients present more than one ST. ${ }^{35,36}$ About $71.8 \%$ of patients in this study presented a single ST, while $23.2 \%$ of all cases presented two STs, and $5 \%$ of cases presented more than two (multiple hyperdontia) (- Fig. 3 ).

Liu at al $^{22}$ obtained single STs in $72 \%$ of patients, two STs in $27 \%$, and cases of multiple hyperdontia in only $0.6 \%$. Bereket et $\mathrm{al}^{26}$ found cases of single STs in $77.4 \%$ of their study population, while multiple hyperdontia was observed in $4.12 \%$.

Yusof $^{37}$ claimed that multiple hyperdontia is most commonly located in the mandibular premolar region ( $45 \%$ of cases). The present study obtained a very similar percentage, as supernumerary premolars represented $45.6 \%$ of STs in multiple hyperdontia; as might be expected, mandibular premolars were much more frequent (40\%) than maxillary 


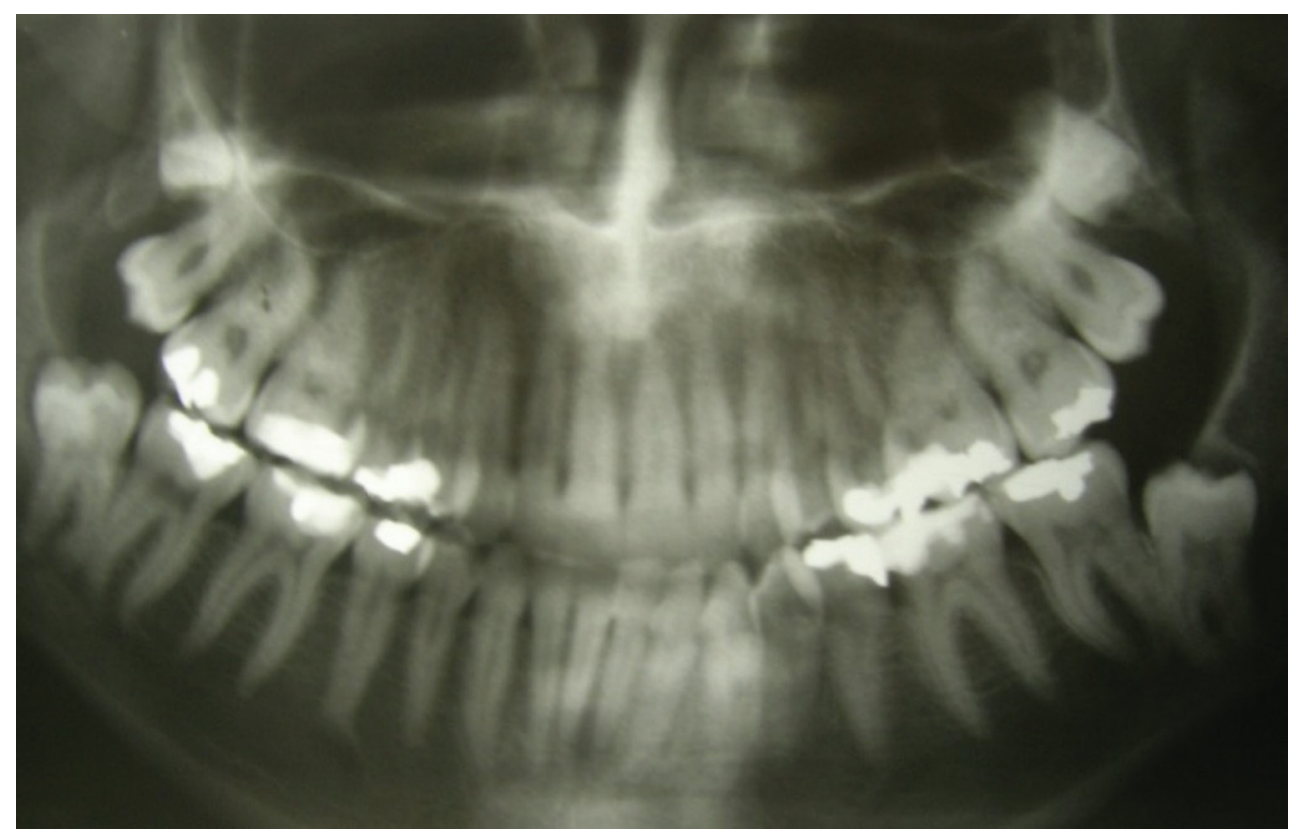

Fig. 1 Panoramic radiograph showing distomolars in upper right and left quadrants. Both of them impacted and presenting supplementary morphology.

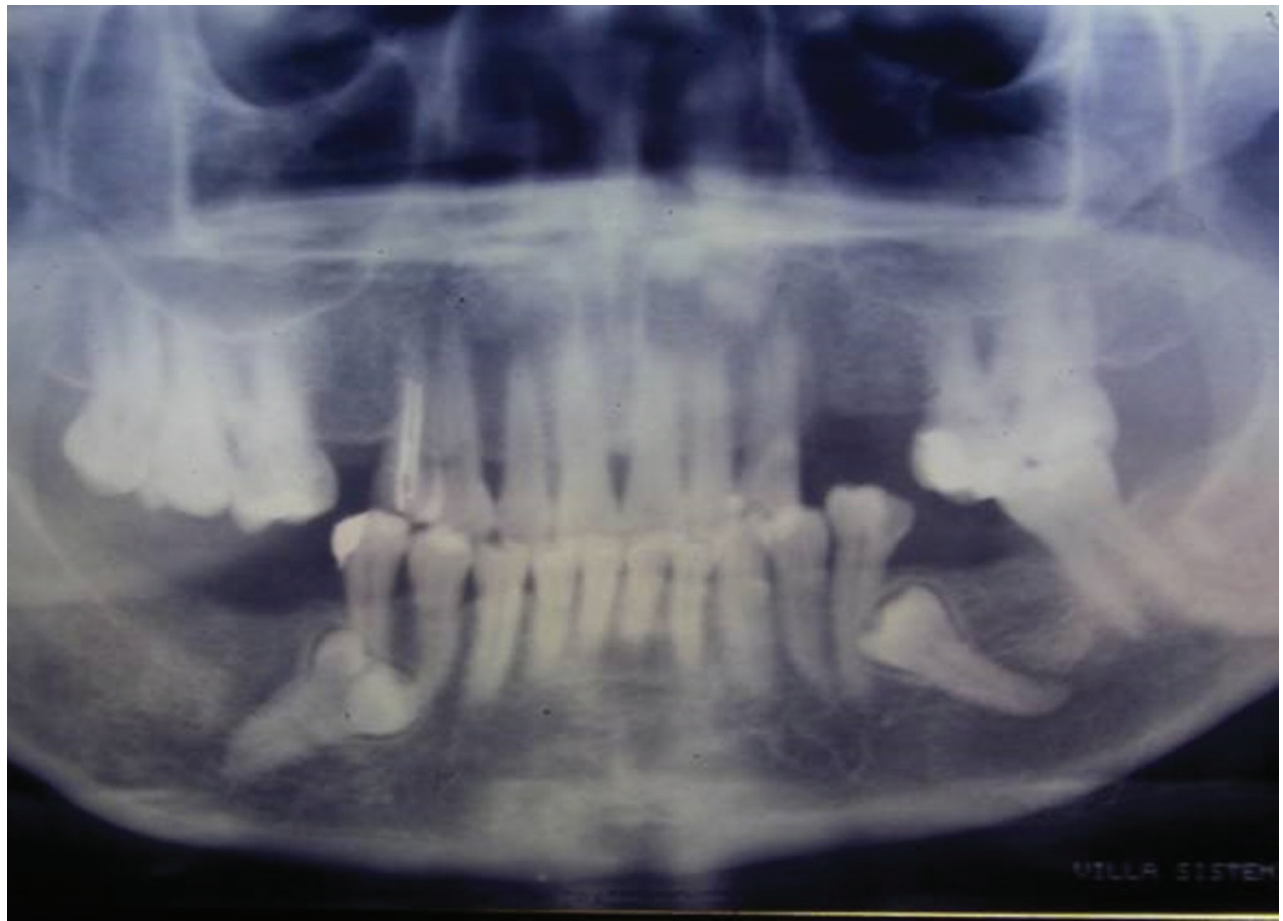

Fig. 2 Panoramic radiograph showing three impacted supernumerary premolars in mandible; one in quadrant three and two in quadrant four. The supernumerary premolars shapes are nearly identical to their homologous teeth.

premolars. Distomolars were the second most common type of ST (33.3\%) in cases of multiple hyperdontia.

According to the literature, STs are usually impacted. In fact, only $25 \%$ of STs erupt, the rest remain impacted, which means that early diagnosis can be important. ${ }^{1}$

Out of the 726 STs included in the present study, 566 were impacted (78\%) and 160 had erupted (22\%). Rajab and Hamdam ${ }^{19}$ and De Oliveira Gomes et $\mathrm{a}^{23}$ among others affirm that the impaction of STs occurs in some $75 \%$ of cases.
Meanwhile, authors such as Salcido-García et $\mathrm{al}^{9}$ and Leco Berrocal et $\mathrm{al}^{24}$ have obtained higher percentages of over $90 \%$.

Analyzing the morphology of the STs identified in the present study, 378 teeth $(52.1 \%)$ presented supplementary morphology and 348 teeth (47.9\%) showed heteromorphic morphology.

Determining dental morphology from panoramic and intraoral (periapical and/or occlusal) radiographs presents inherent difficulties. For this reason, the present study 


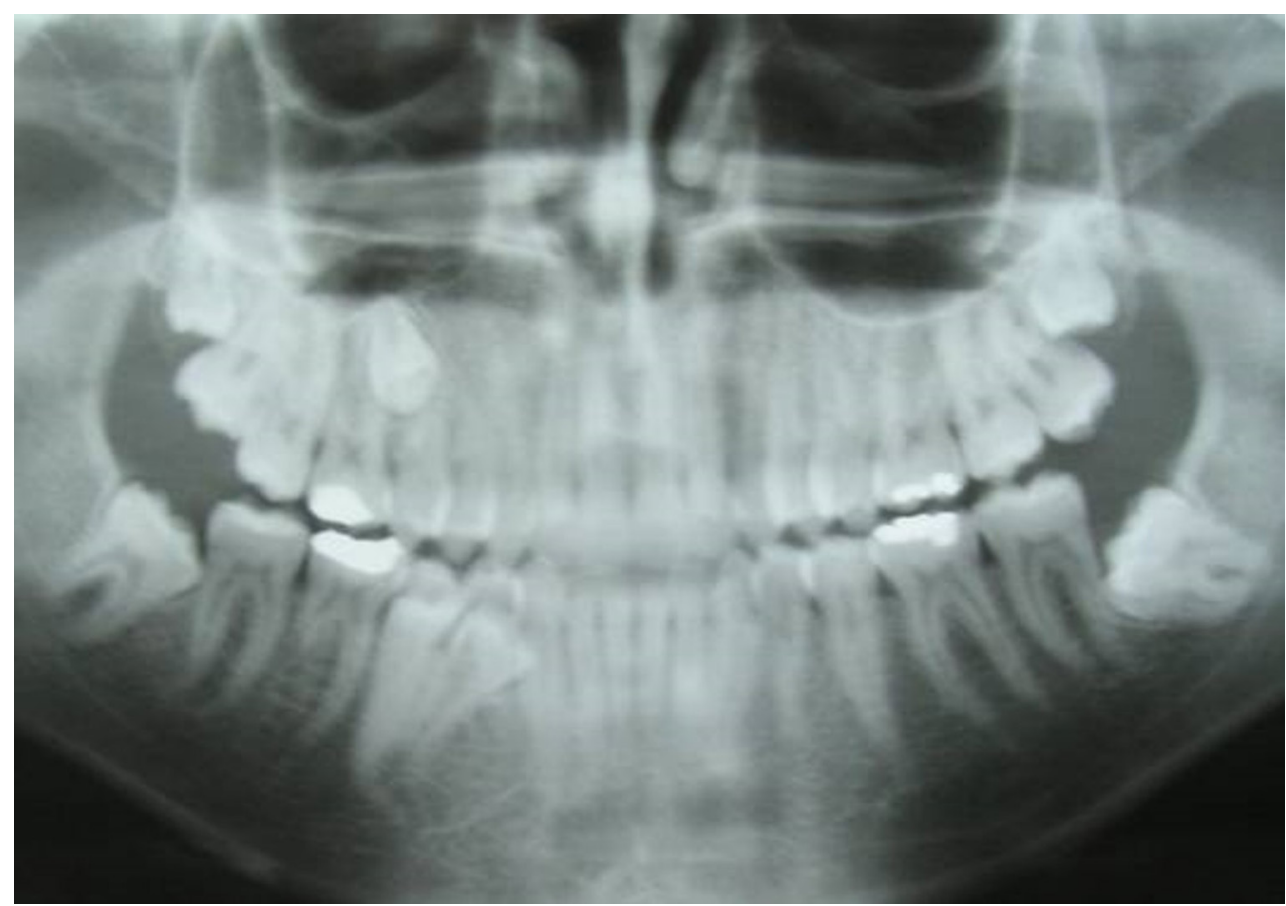

Fig. 3 Panoramic radiograph showing multiple impacted supernumerary teeth. One distomolar in quadrant one and another distomolar in quadrant two. Both presented supplementary morphology. Besides 3 supernumerary premolars, one in quadrant one and two in quadrant four. All of them presented supplementary morphology.

attempted to standardize the classification of morphology; however, these findings were verified after surgical extraction of the ST.

Anthonappa et $\mathrm{al}^{21}$ obtained supplementary morphology in $10.9 \%$ of STs, heteromorphic morphology being much more frequent (89.1\%). Fernández Montenegro et $\mathrm{al}^{27}$ found heteromorphic morphology to be the most usual tooth shape (75.8\% of cases). De Oliveira Gomes et $\mathrm{a}^{23}$ observed supplementary morphology in $16.7 \%$ of the STs analyzed in their study, while Rajab and Hamdan ${ }^{19}$ obtained an even lower percentage of STs with supplementary morphology (6.9\%), with $93.1 \%$ presenting heteromorphic morphology.

The present study identified a statistically significant relationship ( $p=0.000$ ) between ST type and morphology; $91.7 \%$ of paramolars and $86.1 \%$ of mesiodens presented heteromorphic morphology, while $100 \%$ of upper lateral incisors and $90.4 \%$ of supernumerary premolars had identical shapes to their homologous teeth.

One of the objectives in the present study was to analyze clinical complications associated with STs. It was observed that $39.7 \%(n=288)$ of the STs analyzed presented some associated pathology. While $25.1 \%$ ( $n=182$ ) of cases presented MOP, $13.5 \%(n=98)$ of STs presented FSE $>3 \mathrm{~mm}$. Eight STs (1.1\%) were associated with both pathologies. Authors such as Eliasson et $\mathrm{a}^{38}$ and Sewerin and von Wowern ${ }^{39}$ have investigated FSE $>3 \mathrm{~mm}$ in patients with impacted third molars. The results showed that this enlargement is not frequent (6.0\% and $5.45 \%$ respectively) but when enlargement does appear, the results of histological analysis were compatible with follicular cysts.

The present results concur with those of Bereket et $\mathrm{al}^{26}$ and Celikoglu et $\mathrm{al}^{30}$ who found a percentage of pathology associated with STs of 38.36 and $45.83 \%$, respectively, mechanical pathology being more common. Bereket et a ${ }^{26}$ observed cystic degeneration in $0.63 \%$ of cases, while Celikoglu et $\mathrm{a}^{30}$ did not find any cases of this pathology.

De Oliveira Gomes et $\mathrm{al}^{23}$ found a higher percentage of associated pathology; $88.5 \%$ of the 460 STs included in their study were associated with some type of pathology. Nevertheless, it should be noted that the percentage of cystic pathology was low (0.6\%).

An observational study by Leco Berrocal et $\mathrm{al}^{24}$ of the frequency of STs in a population of 2,000 patients found associated pathology in $73 \%$ of STs; $54 \%$ were mechanical and $19 \%$ presented associated follicular cysts

In the present sample, a statistically significant relation $(p=0.000)$ was found between ST type and the presence of associated pathology. Twenty-six percent of supernumerary premolars were associated with FSE $\geq 3 \mathrm{~mm}$, this being the ST type most frequently associated with this pathology. In order of frequency, premolars were followed by distomolars (19\%), canines (15.4\%), and paramolars (2.7\%). At the same time, paramolars were the tooth type most frequently associated with mechanical pathology (58.3\%); paramolars were followed by lateral incisors (42.9\%), canines (38.5\%), mesiodens (36.1\%), distomolars (21.2\%), lower incisors (20\%), and premolars (2.7\%).

The high percentage of FSE $\geq 3 \mathrm{~mm}$ (26\%) associated with supernumerary premolars found in the present study is noteworthy, and contrasts sharply with results obtained by Bodin et $\mathrm{al}^{40}$ who only observed this pathology in $2 \%$ of supernumerary premolars.

However, the mesiodens analyzed in the present study $(n=144)$ presented a slightly lower percentage of associated 
complications than the overall mean obtained (36.1 vs. 39.7\%). No mesiodens was found to be associated with FSE $\geq 3 \mathrm{~mm}$.

Bivariate analysis also revealed a statistically significant relationship ( $p=0.000)$ between ST location and associated pathology. In spite of the absence of general differences in percentages between the upper and lower arches (39.3\% in the mandible and $39.8 \%$ in the maxilla), when differences were analyzed in terms of the type of associated pathology, FSE $\geq 3 \mathrm{~mm}$ was more frequent in the mandible (23.4\% but only $9.4 \%$ in the maxilla). Meanwhile, mechanical pathology was more frequent in the maxilla (30.5\% compared with $12.1 \%$ in the mandible). Bearing in mind that supernumerary premolars represent over 50\% (60.75\%) of all mandibular STs in the present study and that $26 \%$ of these premolars presented FSE $\geq 3 \mathrm{~mm}$, then this type of pathology showed a high incidence in the mandible. As far as we are aware, the literature does not include any previous study that has analyzed these variables together.

\section{Conclusions}

This study analyzed the epidemiological characteristics and clinical repercussions of $726 \mathrm{ST}$. Although mesiodens is considered the most common ST, the present study found distomolars and supernumerary premolars to be the most frequently occurring. Pathology was associated with $39.7 \%$ of the ST sample. However, early diagnosis allows optimal patient management and treatment planning, with intervention at an appropriate time to prevent complications in development and so reduce later treatment need

\section{Conflict of Interest}

None declared.

\section{References}

1 Russell KA, Folwarczna MA. Mesiodens-diagnosis and management of a common supernumerary tooth. J Can Dent Assoc 2003;69(6):362-366

2 Cacahuana-Cárdenas A. Non-erupted anterior supernumerary teeth. Review of 125 cases. RCOE 2003;8(3):263-271

3 Gallas MM, García A. Retention of permanent incisors by mesiodens: a family affair. Br Dent J 2000;188(2):63-64

4 Orhan AI, Özer L, Orhan K. Familial occurrence of nonsyndromal multiple supernumerary teeth. A rare condition. Angle Orthod 2006;76(5):891-897

5 Camilleri GE. Concomitant hypodontia and hyperodontia. Case report. Br Dent J 1967;123(7):338-339

6 Menardía-Pejuan V, Berini-Aytés L, Gay-Escoda C. Supernumerary molars. A review of 53 cases. Bull Group Int Rech Sci Stomatol Odontol 2000;42(2-3):101-105

7 Liu JF. Characteristics of premaxillary supernumerary teeth: a survey of 112 cases. ASDC J Dent Child 1995;62(4):262-265

8 Nazif MM, Ruffalo RC, Zullo T. Impacted supernumerary teeth: a survey of 50 cases. J Am Dent Assoc 1983;106(2):201-204

9 Salcido-García JF, Ledesma-Montes $\mathrm{Cl}$, Hernández-Flores $\mathrm{F}$, Pérez D, Garcés-Ortiz M. Frecuencia de dientes supernumerarios en una población mexicana. Med Oral Patol Oral Cir Bucal 2004;9(5):403-409

10 Ezoddini AF, Sheikhha MH, Ahmadi H. Prevalence of dental developmental anomalies: a radiographic study. Community Dent Health 2007;24(3):140-144
11 Domínguez Reyes A, Mendoza Mendoza A, Fernández Domínguez $\mathrm{H}$. Estudio retrospectivo de dientes supernumerarios en 2045 pacientes. Av Odontoestomatol 1995;11(8):575-582

12 Asaumi JI, Hisatomi M, Yanagi Y, et al. Evaluation of panoramic radiographs taken at the initial visit at a department of paediatric dentistry. Dentomaxillofac Radiol 2008;37(6):340-343

13 Davis PJ. Hypodontia and hyperdontia of permanent teeth in Hong Kong schoolchildren. Community Dent Oral Epidemiol 1987;15(4):218-220

14 Huang WH, Tsai TP, Su HL. Mesiodens in the primary dentition stage: a radiographic study. ASDC J Dent Child 1992;59(3):186-189

15 Harris EF, Clark LL. An epidemiological study of hyperdontia in American blacks and whites. Angle Orthod 2008;78(3):460-465

16 Weber FN. Supernumerary teeth. Dent Clin North Am 1964;9(2):509-517

17 Brook AH, Jernvall J, Smith RN, Hughes TE, Townsend GC. The dentition: the outcomes of morphogenesis leading to variations of tooth number, size and shape. Aust Dent J 2014;59(Suppl 1) :131-142

18 Peltola JS. A panoramatomographic study of the teeth and jaws of Finnish university students. Community Dent Oral Epidemiol 1993;21(1):36-39

19 Rajab LD, Hamdan MA. Supernumerary teeth: review of the literature and a survey of 152 cases. Int J Paediatr Dent 2002;12(4):244-254

20 Ranalli DN, Buzzato JF, Braun TW, Murphy SM. Long-term interdisciplinary management of multiple mesiodens and delayed eruption: report of case. ASDC J Dent Child 1988;55(5):376-380

21 Anthonappa RP, Omer RS, King NM, King NM. Characteristics of 283 supernumerary teeth in southern Chinese children. Oral Surg Oral Med Oral Pathol Oral Radiol Endod 2008;105(6):e48-e54

22 Liu DG, Zhang WL, Zhang ZY, Wu YT, Ma XC. Three-dimensional evaluations of supernumerary teeth using cone-beam computed tomography for 487 cases. Oral Surg Oral Med Oral Pathol Oral Radiol Endod 2007;103(3):403-411

23 De Oliveira Gomes C, Drummond SN, Jham BC, Abdo EN, Mesquita RA. A survey of 460 supernumerary teeth in Brazilian children and adolescents. Int J Paediatr Dent 2008;18(2):98-106

24 Leco Berrocal MI, Martín Morales JF, Martínez González JM. An observational study of the frequency of supernumerary teeth in a population of 2000 patients. Med Oral Patol Oral Cir Bucal 2007;12(2):E134-E138

25 Burgess JO. A panoramic radiographic analysis of Air Force basic trainees. Oral Surg Oral Med Oral Pathol 1985;60(1):113-117

26 Bereket C, Çakır-Özkan N, Şener İ, Bulut E, Baştan Aİ. Analyses of 1100 supernumerary teeth in a nonsyndromic Turkish population: a retrospective multicenter study. Niger J Clin Pract 2015;18(6):731-738

27 Fernández Montenegro P, Valmaseda Castellón E, Berini Aytés L, Gay Escoda C. Retrospective study of 145 supernumerary teeth. Med Oral Patol Oral Cir Bucal 2006;11(4):E339-E344

28 Dauder MD, Peñarrocha M, Sanchís JM. Estudio retrospectivo de dientes supernumerarios en 1013 pacients. Av Odontoestomatol 1998;3:127-129

29 TochiharaY. Studies of supernumerary in Japanese I. J Tokyo Dent Coll Soc 1935;40:651-664

30 Celikoglu M, Kamak H, Oktay H. Prevalence and characteristics of supernumerary teeth in a non-syndrome Turkish population: associated pathologies and proposed treatment. Med Oral Patol Oral Cir Bucal 2010;15(4):e575-e578

31 Grimanis GA, Kyriakides AT, Spyropoulos ND. A survey on supernumerary molars. Quintessence Int 1991;22(12):989-995 
32 Rubenstein LK, Lindauer SJ, Isaacson RJ, Germane N, Richmond $\mathrm{V}$, Augusta G. Development of supernumerary premolars in an orthodontic population. Oral Surg Oral Med Oral Pathol 1991;71(3):392-395

33 Scanlan PJ, Hodges SJ. Supernumerary premolar teeth in siblings. Br J Orthod 1997;24(4):297-300

34 Martínez-González JM, Brinkmann JC, Calvo-Guirado JL, AriasIrimia O, Barona-Dorado C. A clinical epidemiologic analysis of a sample of 73 supernumerary premolars. J Am Dent Assoc 2010;141(12):1435-1441

35 Kim SG, Lee SH. Mesiodens: a clinical and radiographic study. J Dent Child (Chic) 2003;70(1):58-60

36 Cortés-Bretón Brinkmann J, Barona-Dorado C, MartínezRodríguez N, Martín-Ares M, Martínez-González JM. Nonsyndromic multiple hyperodontia in a series of 13 patients: epidemiological and clinical considerations. J Am Dent Assoc 2012;143(6):e16-e24

37 Yusof WZ. Non-syndrome multiple supernumerary teeth: literature review. J Can Dent Assoc 1990;56(2):147-149

38 Eliasson S, Heimdahl A, Nordenram A. Pathological changes related to long-term impaction of third molars. A radiographic study. Int J Oral Maxillofac Surg 1989;18(4):210-212

39 Sewerin I, von Wowern N. A radiographic four-year follow-up study of asymptomatic mandibular third molars in young adults. Int Dent J 1990;40(1):24-30

40 Bodin I, Julin P, Thomsson M. Hyperodontia. I. Frequency and distribution of supernumerary teeth among 21,609 patients. Dentomaxillofac Radiol 1978;7(1):15-17 